\title{
Methodology for Identifying the Best Equations for Estimating the Time of Concentration of Watersheds in a Particular Region
}

\author{
Soroosh Sharifi ${ }^{1}$ and Seyed Mahmood Hosseini ${ }^{2}$
}

\begin{abstract}
In this paper, a methodology is proposed for identifying the best equations for estimating the time of concentration (ToC) of watersheds located in a specific geographic region. The methodology primarily works on the basis of modifying available equations to minimize their bias for any particular region of interest. In the methodology, for each watershed, the ToC considered as "reference" is determined using the Natural Resource Conservation Service (NRCS) velocity method employed in the TR-55 model and geographic information systems data. Moreover, a ranking-based selection strategy is developed for evaluating and selecting the best performing methods. In a case study, the proposed methodology is applied to 72 watersheds and subwatersheds in Khorasan Razavi province, Iran. According to the study, the California equation (with a correction factor of 1.715), the Kirpich (Tennessee) equation (with a correction factor of 1.721), and the Arizona DOT equation (with a correction factor of 1.126) have the best performance for the selected watersheds. DOI: 10.1061/ (ASCE)IR.1943-4774.0000373. (C) 2011 American Society of Civil Engineers.
\end{abstract}

CE Database subject headings: Geographic information systems; Time factors; Velocity; Watersheds; Estimation; Iran.

Author keywords: Geographic information systems (GIS); Hydrology; Time of concentration; Velocity method.

\section{Introduction}

Almost all hydrologic analyses require one or more time-scale parameters as input. Among all time parameters, the time of concentration (ToC) is the most frequently utilized time parameter (McCuen et al. 1984; Wong 2009). This parameter reflects the speed at which the watershed responds to rainfall events (Pavlovic and Moglen 2008) and hence is of great importance in many hydrological analyses (Fang et al. 2008). For instance, the design of urban storm water drainage systems using the rational method requires an estimate of $\mathrm{ToC}$ for selecting the design rainfall intensity from the intensity duration frequency (IDF) curves (Viessman and Lewis 2003). Furthermore, rainfall-runoff models such as TR-55 [Natural Resource Conservation Service (NRCS) 1986], TR-20 (NRCS 1986) and HEC-HMS [U.S. Army Corps of Engineers (USACE) 2001] demand an estimation of the ToC to predict the peak discharge, which is used for design purposes such as storm water management systems, bridge/culvert openings, and spillways. Accurate estimates of the ToC are important; if ToC is underestimated, the result is an overestimated peak discharge and vice versa (Fang et al. 2007).

Recognizing its importance, hydrologists have developed many empirical and semiempirical methods for estimating the

${ }^{1}$ Formerly, Graduate Student, Ferdowsi Univ., Mashhad, Iran; and Postdoctoral Researcher, Civil Engineering Dept., Catholic Univ. of America, 620 Michigan Ave. N.E., Washington, DC 20064 (corresponding author). E-mail: Soroosh.Sharifi@Gmail.com

${ }^{2}$ Associate Professor, Civil Engineering Dept., Ferdowsi Univ. of Mashhad, P.O. Box 91775-1111, Mashhad, Iran. E-mail: Shossein@ Ferdowsi.um.ac.ir

Note. This manuscript was submitted on November 3, 2010; approved on April 25, 2011; published online on May 25, 2011. Discussion period open until April 1, 2012; separate discussions must be submitted for individual papers. This paper is part of the Journal of Irrigation and Drainage Engineering, Vol. 137, No. 11, November 1, 2011. CASCE, ISSN $0733-$ 9437/2011/11-712-719/\$25.00.
ToC. However, modelers are often confused by the number of ToC estimation methods and formulas and often select a method without evaluating and comparing its accuracy with other methods (McCuen et al. 1984; Wong 2005). There have been earlier attempts to assess the accuracy of some of these methods. For instance, using the estimations of the NRCS velocity method as the "true" value of ToC, McCuen et al. (1984) reviewed and evaluated 11 empirical equations used for estimating ToC in urban watersheds. In another study, McCuen and Spiess (1995) analyzed limiting criteria in computing the $\mathrm{ToC}$ for sheet flow from kinematic wave theory. Wong (2005) also assessed the accuracy of nine formulas for overland flow subjected to uniform rain with the experimental values derived for concrete and grass surfaces under the same conditions.

The applicability of commonly used empirical ToC estimation methods is constrained by the lack of diversity in the data used for their development. Hence, these simple methods that are extremely popular because of their limited number of input parameters are often used without considerable caution. This research follows the previous work and proposes a methodology for identifying the most accurate empirical $\mathrm{ToC}$ estimation method(s) for application in a particular region. In a case study, the methodology is applied to a range of watershed conditions in Khorasan Razavi province of Iran to identify the best-performing method from nine widely used empirical and semiempirical ToC estimation methods.

The paper is organized as follows. The first section provides a brief background on ToC and its common estimation methods. Then, the methodology for finding the hydraulically justifiable, reference ToC is proposed, followed by the method selection procedure. Next, the watershed data used in the case study is briefly discussed. Finally, the results obtained from applying the methodology are presented. 


\section{Background}

The numerous developed ToC estimation methods are primarily based on two commonly accepted definitions of this parameter. In the first definition, ToC is the time required for runoff to travel from the hydraulically most distant point of the watershed to the outlet or design point (Kirpich 1940; McCuen et al. 1984; Sing 1988). Methods based on this definition use the watershed's characteristics (e.g., area, slope, and channel roughness) along with some rainfall attributes (e.g., the 2-year, 2-h rainfall intensity) to estimate ToC. The second definition defines $\mathrm{ToC}$ as the time distance between the center of mass of rainfall excess and the inflection point of the falling limb of the direct runoff hydrograph (McCuen et al. 1984; Sing 1988).

Because of the subjective selection of the input parameters by the modeler, methods based on either of these definitions will not always result in unique and repeatable estimations of the ToC (McCuen et al. 1984). Furthermore, many methods are developed for watersheds in a specific region and for a dominant flow regime (i.e., sheet flow or channel flow). As a result, a global exact method for estimating the ToC does not exist, and hence the true value of this parameter can never be determined (McCuen et al. 1984). In other words, because of the subjectivity in selecting single values for spatially variable input parameters (e.g., a single value for the channel roughness coefficient) and also the method of analysis, uncertainty is an inherent feature of all estimation methods. Therefore, for a specific region of interest, one can concentrate on selecting the most accurate method(s) available in the literature and apply modifications if necessary.

ToC estimation methods can be categorized into two major categories (Wong 2009): (1) lumped methods, and (2) distributed methods. In lumped methods, the ToC of the watershed is estimated through one formula that essentially includes the flow times on the overland surface and through the drainage channel. Most empirical methods, which are typically developed using regression analysis, such as the Carter (1961) and Kirpich (1940) methods, fall in this category. In distributed methods, the flow time of each flow regime is calculated individually and then summed to give the ToC. Distributed methods such as the NRCS (1986) velocity method generally require a relatively larger number of input parameters and are thought to give better estimations of ToC (Yen 1982; Kibler and Aron 1983).

The primary issue for evaluating ToC estimation methods is that the "true" value of ToC, which is influenced by variations of rainfall characteristics, topographic setting, and channel characteristics, cannot be directly measured or determined. Hence, the first step in identifying the most proper estimation method would be to select an estimation method that can give accurate estimations of this time parameter that are reliable enough to be treated as the true value. Because the NRCS velocity method relies on a solid hydraulic basis for estimating flow velocity (Fang et al. 2007) and also evidencing a close agreement between the mean ToC computed by this method and the mean time computed from rainfall and hydrograph data (McCuen et al. 1984), this method has been commonly selected as the most accurate method for calculating the ToC of urban and

Table 1. Summary of the Empirical and Semiempirical ToC Estimation Methods Selected for Evaluation

\begin{tabular}{|c|c|c|}
\hline Method & Equation for $\mathrm{ToC}(\mathrm{h})$ & Remarks \\
\hline Carter (1961) & $T_{c}=0.0015476 L^{0.6} S^{-0.3}$ & $\begin{array}{l}\text { - Developed for urban watersheds } \\
\text { - Area less than } 20.7199049 \mathrm{~km}^{2}\left(8 \mathrm{mi}^{2}\right) \\
\text { - Channel length less than } 11.265408 \mathrm{~km}(7 \mathrm{mi}) \\
\text { - } 0.013 \& l t ;=\mathrm{n} \& l t ;=0.025 \\
\text { - Significant pipe flow in the basin }\end{array}$ \\
\hline FAA (1970) & $T_{c}=0.0165626(1.1-C) L^{0.5}(100 S)^{-0.333}$ & $\begin{array}{l}\text { - Developed from airfield drainage data } \\
\text { - Valid for small watersheds where sheet flow } \\
\text { and overland flow dominate }\end{array}$ \\
\hline $\begin{array}{l}\text { Kinematic wave formula } \\
\text { (Aron and Erborge 1973) }\end{array}$ & $T_{c}=0.0319639 L^{0.6} n^{0.6} i^{-0.4} S^{-0.3}$ & $\begin{array}{l}\text { - Developed from kinematic wave analysis of } \\
\text { surface runoff from developed surfaces }\end{array}$ \\
\hline Kerby (1959) Hathaway (1945) & $T_{c}=0.024068 L_{c}^{0.47} n^{0.47} S_{c}^{-0.235}$ & $\begin{array}{l}\left.\text { - Area }<0.0404685642 \mathrm{~km}^{2} \text { (10 acres }\right) \\
\text { - Slopes }<1 \% \\
\text { - } N<0.8\end{array}$ \\
\hline Kirpich (Tennessee) (1940) & $T_{c}=0.0003245 L^{0.77} S^{-0.385}$ & $\begin{array}{l}\text { - Area from } 0.00404685642-0.453247919 \mathrm{~km}^{2}(1-112 \text { acres }) \\
\text { - Slope from } 3 \text { to } 10 \%\end{array}$ \\
\hline NRCS (1972) lag equation & $T_{c}=0.0002269 L^{0.8}(1,000 / C N-9)^{0.7} S^{-0.5}$ & $\begin{array}{l}\text { - For small rural watersheds where overland } \\
\text { flow dominates } \\
\text { - Watershed area }<8.09371284 \mathrm{~km}^{2}(2,000 \text { acres })\end{array}$ \\
\hline Arizona DOT (1993) & $T_{c}=0.0097956 A^{0.1} L^{0.25} L_{c a}^{0.25} S^{-0.2}$ & $\begin{array}{l}\text { - Modified form of FAA } \\
\text { - Agricultural watersheds }\end{array}$ \\
\hline Giandotti (1934) (after Fang et al. 2005) & $T_{c}=\left(4 A^{0.5}+1.5 L_{c}\right) /\left[0.8\left(H-E_{o}\right)\right]^{0.5}$ & $\begin{array}{l}\text { - Developed for small agricultural watersheds } \\
\text { in Italy }\end{array}$ \\
\hline $\begin{array}{l}\text { California Culvert Practice }{ }^{a} \\
\text { (California Division of Highways 1960) }\end{array}$ & $T_{c}=\left(0.871 L^{3} \Delta H^{-1.0}\right)^{0.385}$ & $\begin{array}{l}\text { - Developed for small mountainous watersheds } \\
\text { in California. }\end{array}$ \\
\hline
\end{tabular}

Note: $A=$ area $\left(\mathrm{km}^{2}\right) ; C=$ runoff coefficient; $C N=$ SCS curve number; $E_{o}=$ elevation of watershed outlet $(\mathrm{m}) ; H=$ average elevation of watershed (m); $\Delta H=$ elevation difference between start and endpoint of the main channel $(\mathrm{m}) ; i=$ rainfall intensity $(\mathrm{mm} / \mathrm{h}) ; L=$ length of the watershed along the main channel from the hydraulically most distant point to outlet (m); $L_{c}=$ length of main channel (m); $L_{\mathrm{ca}}=$ length measured from the concentration point along $L$ to a point on $L$ that is perpendicular to the watershed centroid (m); $n=$ Manning's roughness coefficient; $S=$ average slope of watershed $(\mathrm{m} / \mathrm{m}) ;$ and $S_{c}=$ average slope of main channel $(\mathrm{m} / \mathrm{m})$.

${ }^{\mathrm{a}}$ For the sake of brevity, this method is referred to as the California method in the text. 
nonurban watersheds (Fang et al. 2007). In this paper, this method is also adopted for calculating the ToC values that will be used as the basis for evaluating other empirical methods. This ToC value hereafter will be referred to as the "reference" ToC. In the following subsections, a brief summary of the NRCS velocity method, used for obtaining reference ToC values, and also the empirical methods selected in this study for evaluation and application are provided.

\section{NRCS Velocity Method}

The NRCS (1986) velocity method is a distributed approach in which the ToC is derived by subdividing the longest flow path into small segments and then calculating and summing the flow time of each segment. Three flow regimes, namely, the sheet flow, shallow concentrated flow, and open-channel flow, are distinguished in this method, and equations are defined for calculating the travel time or velocity.

After the initiation of rainfall, at the uppermost portion of the flow path, runoff pathways cannot be well-defined, and sheet flow occurs. The sheet flow travel time is calculated by the kinematic wave equation (Akan and Houghtalen 2003; Pavlovic and Moglen 2008):

$$
T_{\mathrm{sh}}=\frac{0.029(n L)^{0.8}}{P_{2}^{0.5} S^{0.4}}
$$

where $T_{\mathrm{sh}}=$ sheet flow travel time in minutes; $L=$ length of the overland flow in meters (maximum length of $91.44 \mathrm{~m}$ or $300 \mathrm{ft}$ ); $n=$ Manning roughness coefficient; $S=$ average land slope; and $P_{2}=$ 2-year, 24-h rainfall depth in centimeters.

The shallow concentrated flow begins when the sheet flow starts to concentrate into the shallow channels. The average velocity of this portion of a flow is a function of slope and type of the channel (unpaved or paved):

$$
V=k S^{0.5}
$$

where $V=$ velocity; and $k=$ coefficient for the type of the channel, equal to $4.91 \mathrm{~m} \cdot \mathrm{s}^{-1}$ for paved areas and $6.19 \mathrm{~m} \cdot \mathrm{s}^{-1}$ for unpaved areas.

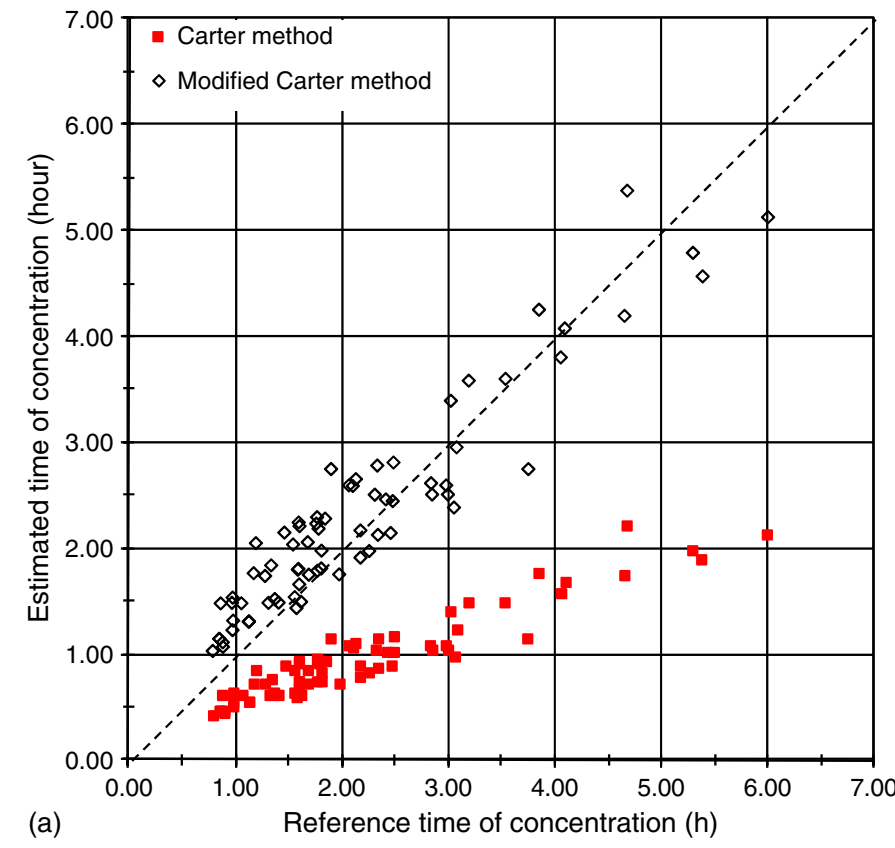

After a distance, the shallow concentrated flow discharges into a channel or pipe. The start of the channel flow is usually from the location where the channel cross section is surveyed or from where it is visible in the aerial images. The water surface profile data or the Manning's equation is used to calculate the velocity:

$$
V=\frac{1}{n} R^{2 / 3} S^{1 / 2}
$$

where $R=$ hydraulic radius. This velocity should be calculated for a normal depth (steady-uniform flow) and bank full conditions. To prevent the trial and error process for finding the hydraulic radius, generally, flows with a return period of 1.5-3 years are used in the calculations (Fang et al. 2005). Once the flow time for each segment of the flow is calculated, the ToC is derived by summing all flow times.

Although the NRCS velocity method is "appealing because of its reliance on hydraulics-based estimates of flow velocity" (Fang et al. 2007), its large number of difficult-to-measure required inputs, such as channel geometry and Manning's roughness coefficient, make this method difficult to apply. Furthermore, the sensitivity of its input parameters makes the estimations heavily dependent on the modeler's assumptions and causes the method to fail to produce repeatable estimates of ToC.

\section{Empirical Methods Selected in this Study for Evaluation and Application}

Most empirical and semiempirical equations proposed in the literature for estimating ToC can be presented as a function of a measured length, a measured slope, and a coefficient that is related to a characteristic of the watershed (Sing 1988; McCuen 1998):

$$
T_{c}=c L^{a} S^{b}
$$

where $a$ and $b=$ exponents that may vary for different watersheds. A roughness coefficient (usually Manning's roughness coefficient) and a rainfall parameter, such as the 2-year, 24-h rainfall depth and rainfall intensity, are other parameters that are frequently observed in empirical methods.

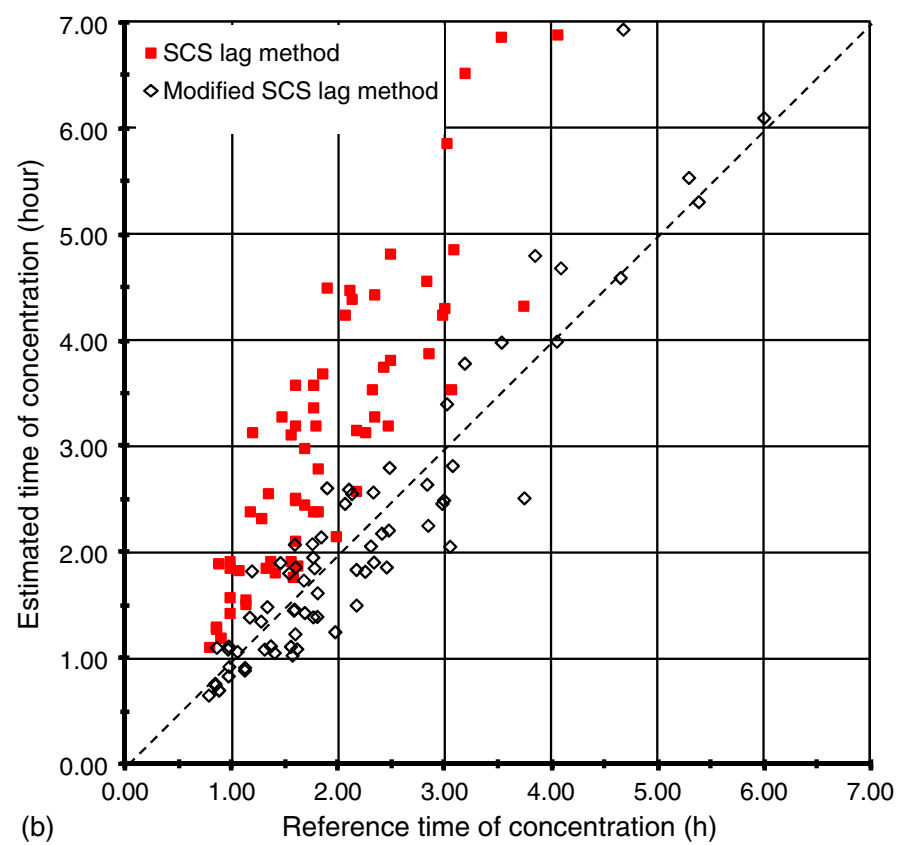

Fig. 1. Estimated versus reference ToC values: (a) Carter method; (b) SCS lag method 


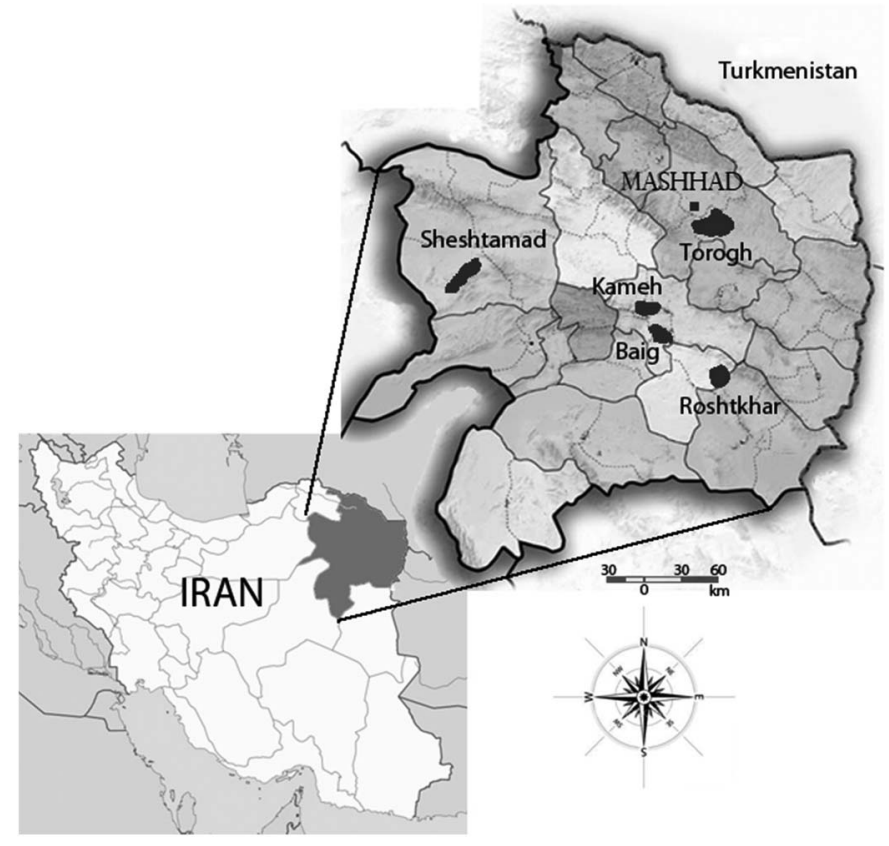

Fig. 2. Location of the selected watersheds in Khorasan Razavi province of Iran

To apply the methodology to a test case, among the many methods proposed in the literature, nine methods were selected for evaluation by using the following criteria. First, the method had to be based on input data that were available in the test data. Second, the methods were among the popular and commonly used methods in the area of study. It is acknowledged that other methods could have been selected; generally, one could choose any set of methods based on availability of data, information, and popularity of methods. Table 1 gives a summary of the selected empirical and semiempirical methods. For a complete review of all other empirical ToC estimation methods, the reader is referred to Singh (1988), Chow et al. (1988), Fang et al. (2005, 2008), and Li and Chibber (2008).

\section{Methodology}

In this section, the methodology for identifying the best ToC estimation method(s) for a particular geographical region is described. First, the method of obtaining reference ToC values by the velocity method using geographic information system (GIS) data is presented. Then, the process of minimizing bias from the empirical methods is explained. This is followed by a description of the ranking-based method selection procedure.

\section{Obtaining the Reference ToC Value}

In this methodology, the TR-55 model (NRCS 1986) incorporated in the Watershed Modeling System (WMS) software was employed to obtain the reference ToC values by using the velocity method. WMS is a comprehensive tool designed to manage GIS and hydrologic data for use in hydrologic models such as TR-55 and HEC-1. Employing GIS tools, this software has the ability to process spatial data and automatically measure some parameters, such as length and slope, and hence can greatly improve the speed and accuracy of the travel times computed in the velocity method (Green and Nelson 2002). To compute the ToC for each watershed, the following steps were performed in WMS:

1. Elevation data were imported into WMS in the form of a digital elevation model (DEM).

2. The flow path network was derived by following the path of steepest descent across the watershed.

3. The outlet points were selected on different locations of the flow network.

4. The hydraulically most distant point was identified, and the flow path between this point and the subwatershed outlet was divided into three segments for the sheet flow, shallow concentrated flow, and the channel flow regimes.

5. A travel time data layer was created, and an equation for calculating the travel time along the flow path line was assigned to each segment.

6. The parameters associated with each equation were defined. Lengths, slopes, and channel cross sections were determined by the GIS tools from the derived flow path segments and spatial data. Other parameters, such as the 2-year 24-h rainfall depth, Manning's roughness coefficient $(n)$, and curve number $(C N)$, were entered separately.

7. Travel times for each segment were calculated and summed to find the ToC.

The obtained value of ToC from this method was considered as the reference value and was used as the basis for evaluating the selected empirical methods. For a more detailed description of the method, see Sharifi (2006) and Green and Nelson (2002).

\section{Minimizing the Bias of the Empirical and Semiempirical Methods}

As noted previously, most empirical methods are the result of analyzing the data gathered from a particular geographic region with specific physical attributes and rainfall patterns. Furthermore, for each method, there always exists some restrictions that limit its applicability, e.g., the regional location of the watershed, valid ranges of watershed area, main stream slope, and the dominant flow regime (i.e., sheet, shallow concentrated, or channel flow).

A preliminary analysis revealed that if the restrictions of the empirical methods are ignored and they are applied to watersheds other than those for which they were developed, they will generally

Table 2. Summary of the Watersheds' General Characteristics

\begin{tabular}{|c|c|c|c|c|c|}
\hline Watershed & Torogh & Kameh & Baig & Roshtkhar & Sheshtamad \\
\hline$A\left(\mathrm{~km}^{2}\right)$ & 376.7 & 56.5 & 33.8 & 57.7 & 18.8 \\
\hline$S(\mathrm{~m} / \mathrm{m})$ & 0.044 & 0.059 & 0.052 & 0.087 & 0.091 \\
\hline$L(\mathrm{~m})$ & 35,309 & 14,407 & 11,609 & 14,397 & 15,335 \\
\hline$\Delta H$ & $1,530.1$ & 834.5 & 556 & $1,203.1$ & $1,381.2$ \\
\hline Precipitation station & Torogh dam & Torbat Heidarieh & Torbat Heidarieh & Roshtkhar & Senobar \\
\hline Latitude & $36^{\circ} 10^{\prime} \mathrm{N}$ & $35^{\circ} 18^{\prime} \mathrm{N}$ & $35^{\circ} 18^{\prime} \mathrm{N}$ & $34^{\circ} 59^{\prime} \mathrm{N}$ & $35^{\circ} 57^{\prime} \mathrm{N}$ \\
\hline Longitude & $59^{\circ} 33^{\prime} \mathrm{E}$ & $59^{\circ} 13^{\prime} \mathrm{E}$ & $59^{\circ} 13^{\prime} \mathrm{E}$ & $59^{\circ} 38^{\prime} \mathrm{E}$ & $57^{\circ} 46^{\prime} \mathrm{E}$ \\
\hline
\end{tabular}


Table 3. Summary Statistics of the Watersheds' Parameters Derived from GIS Data

\begin{tabular}{|c|c|c|c|c|c|c|c|c|c|}
\hline \multicolumn{2}{|c|}{ Parameter } & $\begin{array}{c}A \\
\mathrm{~km}^{2}\end{array}$ & $\begin{array}{c}E_{0} \\
\mathrm{~m}\end{array}$ & $\begin{array}{c}\Delta H \\
\mathrm{~m}\end{array}$ & $\begin{array}{l}L \\
\mathrm{~m}\end{array}$ & $\begin{array}{c}L_{c} \\
\mathrm{~m}\end{array}$ & $\begin{array}{c}L_{\mathrm{ca}} \\
\mathrm{m}\end{array}$ & $\begin{array}{c}S \\
\mathrm{~m} / \mathrm{m}\end{array}$ & $\begin{array}{c}S_{c} \\
\mathrm{~m} / \mathrm{m}\end{array}$ \\
\hline \multirow[t]{4}{*}{ Torogh } & Maximum & 376.693 & $1,740.5$ & $1,530.1$ & $35,308.6$ & $33,710.1$ & $15,603.4$ & 0.114 & 0.096 \\
\hline & Minimum & 8.425 & $1,040.0$ & 202.2 & $5,871.3$ & $4,526.3$ & $2,015.7$ & 0.023 & 0.021 \\
\hline & Mean & 57.397 & $1,269.5$ & 731.0 & $14,567.9$ & $12,796.9$ & $6,666.5$ & 0.053 & 0.040 \\
\hline & Standard deviation & 74.714 & 190.8 & 402.2 & $8,065.2$ & $8,149.5$ & $4,102.7$ & 0.023 & 0.016 \\
\hline \multirow[t]{4}{*}{ Roshtkhar } & Maximum & 57.713 & $1,399.7$ & $1,203.1$ & $14,396.9$ & $14,039.6$ & $7,495.2$ & 0.146 & 0.139 \\
\hline & Minimum & 6.997 & $1,247.9$ & 315.6 & $6,413.5$ & $5,803.6$ & $3,269.6$ & 0.053 & 0.033 \\
\hline & Mean & 21.699 & $1,314.9$ & 836.8 & $9,659.6$ & $9,142.4$ & $4,754.5$ & 0.091 & 0.077 \\
\hline & Standard deviation & 15.862 & 67.7 & 305.3 & $2,781.2$ & $2,809.3$ & $1,421.2$ & 0.030 & 0.034 \\
\hline \multirow[t]{4}{*}{ Kameh } & Maximum & 56.511 & $1,858.5$ & 834.5 & $14,406.8$ & $11,839.3$ & $5,798.2$ & 0.102 & 0.073 \\
\hline & Minimum & 5.347 & $1,696.3$ & 273.4 & $5,415.3$ & $2,777.9$ & 640.9 & 0.044 & 0.028 \\
\hline & Mean & 19.433 & $1,756.8$ & 552.2 & $8,227.4$ & $5,721.3$ & $2,737.2$ & 0.074 & 0.040 \\
\hline & Standard deviation & 17.089 & 59.6 & 205.0 & $2,926.5$ & $2,934.2$ & $1,721.8$ & 0.021 & 0.013 \\
\hline \multirow[t]{4}{*}{ Baig } & Maximum & 33.845 & $1,720.2$ & 556.0 & $11,609.0$ & $10,125.3$ & $4,335.3$ & 0.096 & 0.063 \\
\hline & Minimum & 3.165 & $1,540.2$ & 187.7 & $3,375.6$ & $1,557.0$ & 393.0 & 0.052 & 0.026 \\
\hline & Mean & 10.970 & $1,611.1$ & 390.3 & $6,052.1$ & $4,290.0$ & $1,970.1$ & 0.075 & 0.047 \\
\hline & Standard deviation & 9.574 & 59.8 & 103.3 & $2,637.1$ & $2,830.3$ & $1,259.6$ & 0.014 & 0.010 \\
\hline \multirow[t]{4}{*}{ Sheshtamad } & Maximum & 18.794 & $1,893.3$ & $1,381.2$ & $15,335.3$ & $13,377.8$ & $8,140.8$ & 0.167 & 0.115 \\
\hline & Minimum & 5.779 & $1,376.3$ & 423.2 & $5,311.4$ & $3,353.9$ & $1,076.1$ & 0.059 & 0.048 \\
\hline & Mean & 10.121 & $1,593.2$ & 857.1 & $8,566.2$ & $6,615.2$ & $3,940.0$ & 0.107 & 0.073 \\
\hline & Standard deviation & 5.685 & 219.7 & 398.4 & $4,153.2$ & $3,960.2$ & $2,668.2$ & 0.040 & 0.027 \\
\hline
\end{tabular}

Table 4. Correction Factors for the Selected Empirical Methods

\begin{tabular}{lc}
\hline Method & Correction factor \\
\hline Carter & 2.422 \\
FAA & 2.491 \\
Kinematic wave & 0.844 \\
Kerby-Hathaway & 3.034 \\
Kirpich (Tennessee) & 1.721 \\
SCS lag & 0.578 \\
Arizona DOT & 1.126 \\
Giandotti & 0.964 \\
California & 1.715 \\
\hline
\end{tabular}

show a degree of bias in their estimations, i.e., they will either under- or overestimate the ToC. It was also concluded that if a proper correction factor is introduced into their formulation, the bias will be minimized to a great extent, which will result in improved functionality and higher accuracy of the methods. A comparison was made among a number of adjustment criteria, and the inverse of the linear regression slope between estimated and reference values of ToC was found to be the most proper correction factor for this purpose. This correction factor essentially forces the slope of the regression lines, obtained for each method, to be equal to one. Fig. 1 illustrates the performance of two methods before and after applying the correction factors as examples.

\section{Ranking-Based Method Selection Procedure}

To evaluate, compare, and select the best performing empirical method(s), a ranking-based selection procedure was developed. After obtaining the set of reference and estimated ToC values, they were used in the proposed procedure to evaluate a large set of quantitative goodness-of-fit criteria, aimed at assessing the accuracy and bias of the methods. The mean absolute percentage of errors (MAPE), mean absolute error (MAE), root mean sum of squared errors (RMSE), sum of errors (SE), and coefficient of determination

Table 5. Values of the Selected Goodness-of-Fit Criteria and the Ranking of Methods

\begin{tabular}{lcccccccc}
\hline $\begin{array}{l}\text { Modified } \\
\text { Method }\end{array}$ & Carter & FAA & $\begin{array}{c}\text { Kinematic } \\
\text { wave }\end{array}$ & Kerby-Hathaway & $\begin{array}{c}\text { Kirpich } \\
\text { (Tennessee) }\end{array}$ & SCS lag & Arizona DOT & Giandotti \\
California
\end{tabular}



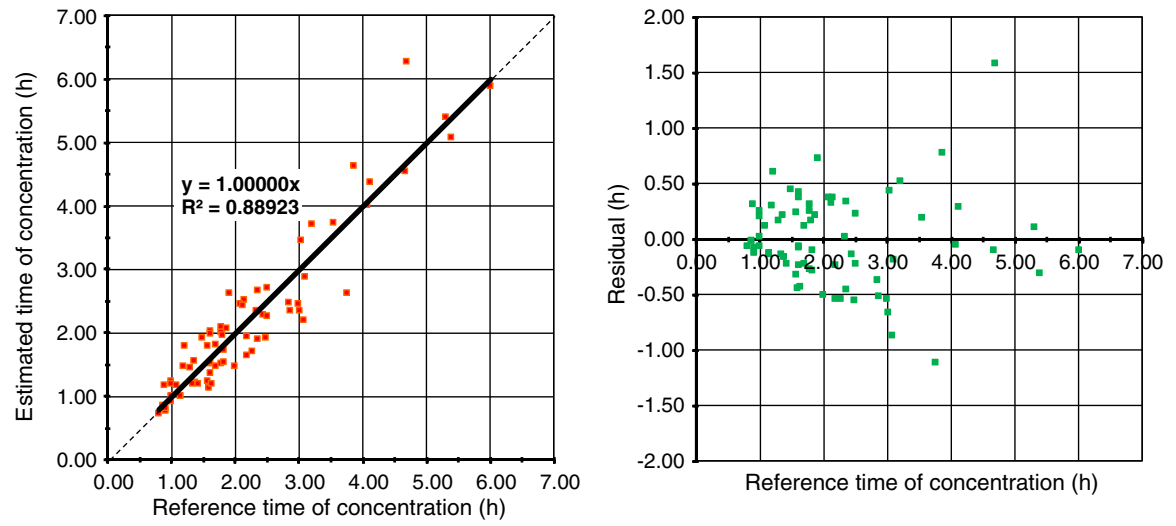

(a)
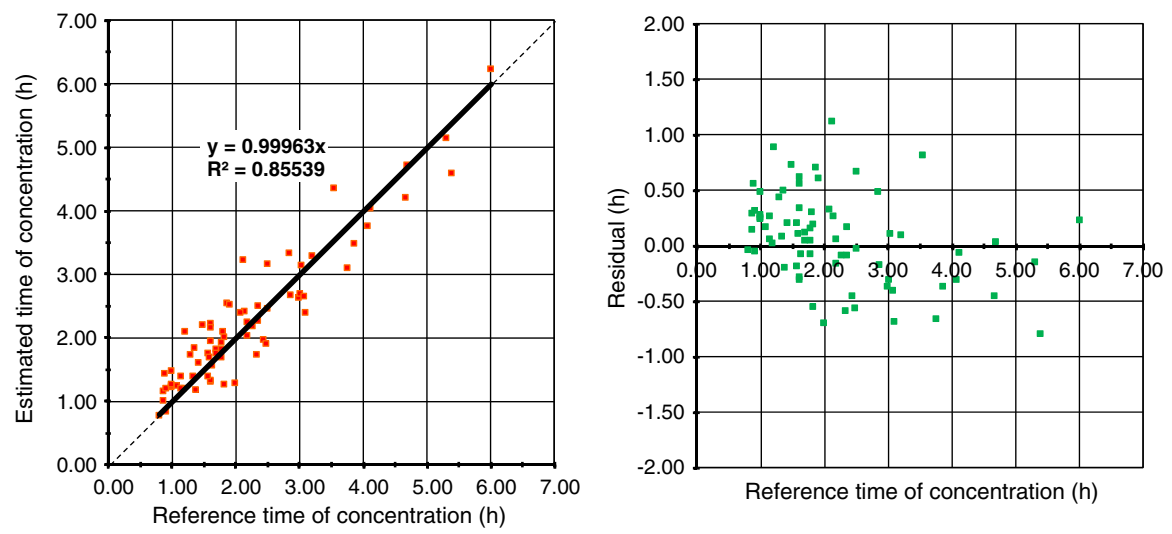

(b)
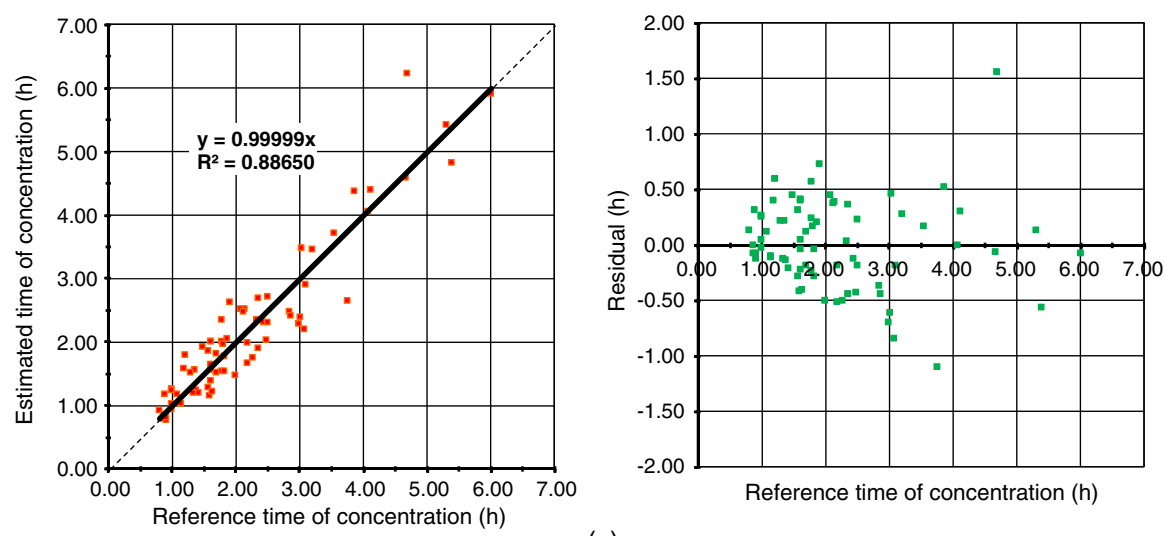

(c)
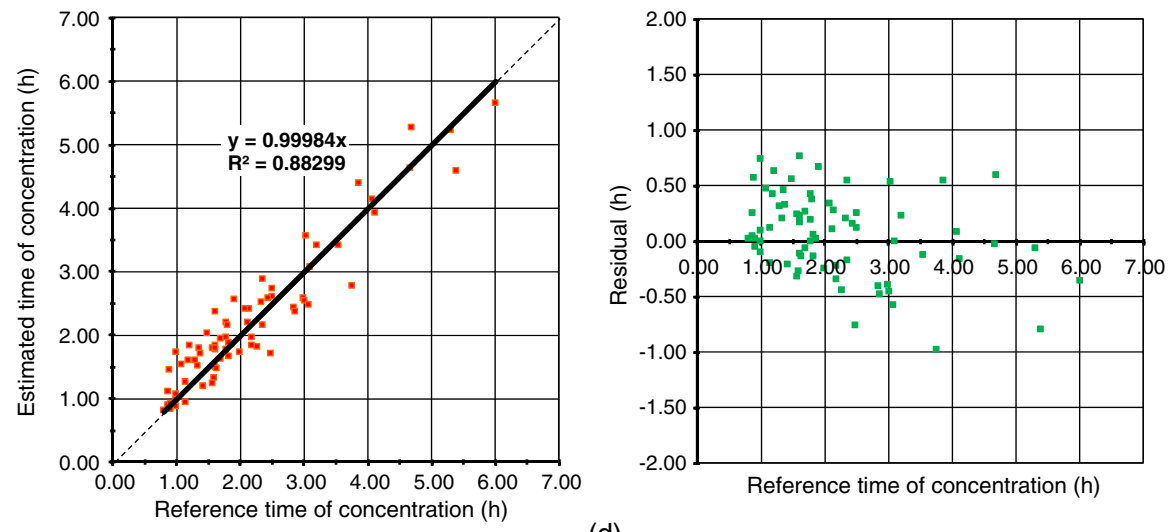

(d)

Fig. 3. Estimated versus reference ToC values and corresponding residual distributions for the top four methods: (a) modified Kirpich (Tennessee) method; (b) modified Giandotti method; (c) modified California method; (d) modified Arizona DOT method 
$\left(R^{2}\right)$ of the linear regression line were selected as the assessment criteria. Then the ranking of the methods for each of the criteria was calculated and summed to give the overall performance ranking. Finally, the overall rankings were used along with the residual plots to make decisions on the final lineup of the methods.

\section{Case Study: Khorasan Razavi Province, Iran}

In a case study, the proposed methodology was applied to a number of watersheds in Khorasan Razavi province, Iran. Although this provincial division is political, all selected watersheds fall within the larger watershed of Gharah-Ghoom in the eastern part of Iran, and the geographical characteristics of the area give a hydrological perspective to this selection. Fig. 2 illustrates the location of the selected watersheds in Khorasan Razavi province of Iran.

\section{General Characteristics of the Selected Watersheds}

The watershed and rainfall data used in this study were obtained through personal contact from a number of sources, including the Khorasan Razavi Water and Wastewater Company and Faraz-band Consulting Engineers. These data included land use, soil type, elevation data, and records of several climate factors. After careful examination of available data sets, five watersheds in the province, namely, Torogh, Kameh, Baig, Roshtkhar, and Sheshtamad, were selected. Table 2 shows a summary of the main characteristics of the selected watersheds. Several subwatersheds within the selected larger watersheds were also identified and used in the study in order to have a wide range of watershed conditions within the chosen geographic region. The summary statistics of the watersheds' main parameters, derived from GIS data and used in different ToC equations, are presented in Table 3.

\section{Applying the Methodology}

First, the methodology for obtaining ToC values using the TR-55 model and the NRCS velocity method was applied, and the reference ToC was obtained for 72 selected watersheds and subwatersheds. Then, disregarding their restrictions and limitations, the selected empirical and semiempirical methods were used to calculate the ToC values. Proper correction factors for each of the methods were obtained (Table 4) and their estimations were corrected. Then, the ranking-based procedure was applied to the estimated and reference ToC values. The selected goodnessof-fit criteria were evaluated, and the ranking of each method was obtained (Table 5).

A first look at the evaluated criteria and the sum of rankings (presented in Table 5) reveals that the Carter, Federal Aviation Administration (FAA), kinematic wave, Kerby-Hathaway, and Soil Conservation Service (SCS) lag methods have the lowest rankings in all criteria and do not give accurate estimations. Conversely, four methods, namely, the Kirpich (Tennessee), Giandotti, California, and Arizona DOT methods perform considerably better than the other methods. The sum of rankings for these methods confirms this statement. Fig. 3 illustrates the linear regression between the reference and estimated $\mathrm{ToC}$ values and the residual distribution for these four methods. Visual inspection of the residual plots indicates that in a general sense, the residuals for each recommended equation are unbiased, have a nearly constant variance, and show a reasonable trend. Also, the residuals were found to follow a normal distribution, indicating that the selected models were appropriate for the data set.

A closer look at both the ranking of the rest of the methods and Fig. 3 shows that the modified Giandotti method has the lowest sum of ranking $(=22)$ and provides the least appealing performance in estimating ToC. Among the remaining methods, due to the persistency in acquiring second-highest ranking based on different criteria and the relatively smooth distribution of the residuals, the modified California method is found to be the most acceptable method. The modified Kirpich method seems to have an edge over the Arizona DOT method because it results in a better distribution of the residuals. In conclusion, the following methods are found to be the most appropriate methods for estimating the ToC in Khorasan Razavi's province, respectively:

1. The modified California method (with a correction factor of 1.715);

2. The modified Kirpich (Tennessee) method (with a correction factor of 1.721); and

3. The modified Arizona DOT method (with a correction factor of 1.126).

It is to be noted that the Arizona DOT method has the advantage that its original formulation can be used to predict ToC without resulting in significant errors. This implies that watersheds in the study area have characteristics similar to those of the watersheds used to calibrate the Arizona DOT method.

\section{Conclusions}

Recognizing the importance of ToC in hydrological designs, many methods have been developed for estimating this time parameter. However, the large number of methods available in the literature and their unknown performances have led to confusion in selecting the appropriate method(s). In this paper, a methodology was presented for identifying the best equations for estimating the ToC of watersheds in a particular region. The practical importance of the proposed method is that it eliminates the need for developing a new ToC estimation method for a region. This is done by identifying the best performing method(s) from the large set of available methods in the literature after imposing a simple modification to their structure and following the presented selection procedure. This methodology consists of the following steps:

1. Obtaining the reference ToC values using the NRCS velocity method incorporated in the TR-55 model;

2. Minimizing bias and improving the estimations of empirical methods by introducing the inverse of the linear regression slope between predicted and reference values of ToC as a correction factor in their formulation;

3. Calculating the estimated ToC values using the modified empirical methods; and

4. Applying the ranking-based selection strategy to identify the best-performing method(s).

The methodology was applied to 72 watersheds and subwatersheds located in Khorasan Razavi province of Iran to identify the best performing method from nine selected empirical and semiempirical methods. It was concluded that the most appropriate methods for estimating the $\mathrm{ToC}$ in this region are the modified California method (with a correction factor of 1.715), the modified Kirpich (Tennessee) method (with a correction factor of 1.721), and the modified Arizona DOT (with a correction factor of 1.126), respectively.

\section{Notation}

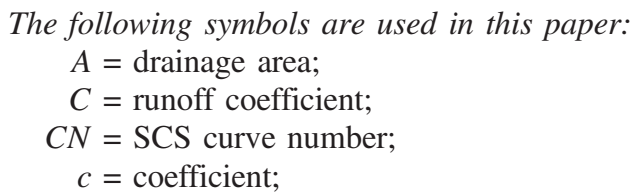


$E$ = elevation;

$H=$ average elevation of watershed;

$i=$ rainfall intensity;

$k=$ coefficient in the shallow concentrated flow regime travel time equation;

$L=$ length;

$n=$ Manning's roughness coefficient;

$P_{2}=$ 2-year, 24-h rainfall depth;

$R=$ hydraulic radius;

$S=$ slope;

$T=$ time; and

$T_{c}=$ time of concentration.

\section{Subscripts}

$c=$ channel;

$o=$ outlet; and

$\mathrm{sh}=$ sheet flow .

\section{References}

Akan, A. O., and Houghtalen, R. J. (2003). Urban hydrology, hydraulics, and stormwater quality: Engineering applications and computer modeling, Wiley, Hoboken, NJ.

Arizona Dept. of Transportation (ADOT). (1993). Highway drainage design manual hydrology, Phoenix.

Aron, G., and Egborge, C. E. (1973). "A practical feasibility study of flood peak abatement in urban areas." U.S. Army Corps of Engineers, Sacramento, CA.

California Division of Highways (CDH). (1960). "California culvert practice." Dept. of Public Works, Division of Highways, Sacramento, CA.

Carter, R. W. (1961). "Magnitude and frequency of floods in suburban areas." Professional Paper 424-B B9-B11, U.S. Geological Survey, Reston, VA.

Chow, V. T., Maidment, D. R., and Mays, L. W. (1988). Applied hydrology, McGraw-Hill, New York.

Fang, X., Cleveland, T., Garcia, C. A., Thomson, D., and Malla, R. (2005). "Literature review on timing parameters for hydrographs." Project Number 0-4696/1, Texas Dept. of Transportation, Austin, TX.

Fang, X., Thompson, D. B., Cleveland, T. G., and Pradhan, P. (2007). "Variations of time of concentration estimates using NRCS velocity method." J. Irrig. Drain Eng., 133(4), 314-322.

Fang, X., Thompson, D. B., Cleveland, T. G., Pradhan, P., and Malla, R. (2008). "Time of concentration estimated using watershed parameters determined by automated and manual methods." J. Irrig. Drain Eng., 134(2), 202-211.

Federal Aviation Administration (FAA). (1970). "Advisory circular on airport drainage.” U.S. Dept. of Transportation, Washington, DC.
Giandotti, M. (1934). "Previsione delle piene e delle magre dei corsi d'acqua." Ministero LL.PP., Memorie e studi idrografici, Vol. 8, Rep. No. 2, Servizio Idrografico Italiano, Rome (in Italian).

Green, J. I., and Nelson, E. J. (2002). "Calculation of time of concentration for hydrologic design and analysis using geographic information system vector objects." J. Hydroinf., 4(2), 75-81.

Hathaway, G. A. (1945). "Design of drainage facilities." Trans. Am. Soc. Civ. Eng., 110, 697-733.

Kerby, W. S. (1959). "Time of concentration for overland flow." Civ. Eng., 26(3), 60

Kibler, D. F., and Aron, G. (1983). "Evaluation of Tc methods for urban watersheds." Proc., Conf. on Frontiers in Hydraulic Engineering, H. T. Shen, ed., ASCE, New York, 553-558.

Kirpich, Z. P. (1940). "Time of concentration of small agricultural watersheds." Civil Eng., 10(6), 362-368.

Li, M. H., and Chibber, P. (2008). "Overland flow time of concentration on very flat terrains." Transportation Research Record 2060, Transportation Research Board, Washington, DC, 133-140.

McCuen, R. H. (1998). Hydrologic analysis and design, Prentice Hall, Upper Saddle River, NJ.

McCuen, R. H., and Spiess, J. M. (1995). "Assessment of kinematic wave time of concentration." J. Hydraul. Eng., 121(3), 256-266.

McCuen, R. H., Wong, S. L., and Rawls, W. J. (1984). "Estimating urban time of concentration." J. Hydraul. Eng., 110(7), 887-904.

Natural Resource Conservation Service (NRCS). (1972). National engineering handbook, Section 4: Hydrology, U.S. Dept. of Agriculture, Washington, DC.

Natural Resource Conservation Service (NRCS). (1986). "Urban hydrology for small watersheds." Tech. Release No. 20, Soil Conservation Service, U.S. Dept. of Agriculture, Washington, DC.

Pavlovic, S. B., and Moglen, G. E. (2008). "Discretization issues in travel time calculation." J. Hydrol. Eng., 13(2), 71-79.

Sharifi, S. (2006). "Identifying the most accurate equations for estimating the time of concentration in suburban watersheds of Khorasan Province by means of geographic information systems." M.Sc. thesis, Ferdowsi Univ. of Mashhad, Iran (in Persian).

Singh, V. P. (1988). Hydrologic systems: Rainfall-runoff modeling, Vol. 1, Prentice Hall, Englewood Cliffs, NJ.

U.S. Army Corps of Engineers (USACE). (2001). "HEC-HMS hydrologic modeling system. User's manual Version 2.2.1."〈www.usace.army .mil $\rangle$.

Viessman, W., Jr., and Lewis, G. L. (2003). Introduction to hydrology, Pearson Education, New York.

Wong, T. S. W. (2005). "Assessment of time of concentration formulas for overland flow." J. Irrig. Drain Eng., 131(4), 383-387.

Wong, T. S. W. (2009). "Evolution of kinematic wave time of concentration formulas for overland flow." J. Hydrol. Eng., 14(7), 739-744.

Yen, B. C. (1982). "Some measures for evaluation and comparison of simulation models." Urban stormwater hydraulics and hydrology, B. C., Yen, ed., Water Resources Publications, Littleton, CO. 